\title{
Intrinsic Bone Defects in Cystinotic Mice
}

Giulia Battafarano, ${ }^{*}$ Michela Rossi, ${ }^{*}$ Laura R. Rega, ${ }^{\dagger}$ Gianna Di Giovamberardino, ${ }^{\ddagger}$ Anna Pastore, ${ }^{\S}$ Matteo D’Agostini, Ottavia Porzio, ${ }^{\mathbb{T} \|}$ Nathalie Nevo, ${ }^{* *}$ Francesco Emma, ${ }^{\dagger, \dagger \dagger}$ Anna Taranta, ${ }^{\dagger}$ and Andrea Del Fattore*

From the Bone Physiopathology Group, * Multifactorial Disease and Complex Phenotype Research Area, the Laboratories of Nephrology ${ }^{\dagger}$ and Molecular Genetics and Functional Genomics, ${ }^{\S}$ Division of Genetic and Rare Diseases, the Research Laboratories, ${ }^{\ddagger}$ the Clinical Laboratory, ${ }^{\natural}$ and the Division of Nephrology, ${ }^{\dagger \dagger}$ Department of Pediatric Subspecialities, Bambino Gesù Children's Hospital, Rome, Italy; the Department of Experimental Medicine, ${ }^{\|}$ University of Rome Tor Vergata, Rome, Italy; and INSERM U1163,** Université Paris Descartes, Institut Imagine, Hôpital Necker Enfants Malades, Paris, France

\author{
Accepted for publication \\ January 24, 2019. \\ Address correspondence to \\ Anna Taranta, Ph.D., Labora- \\ tory of Nephrology, Division \\ of Genetic and Rare Diseases, \\ Bambino Gesù Children's \\ Hospital, Viale San Paolo 15, \\ 00146 Rome, Italy. E-mail: \\ anna.taranta@opbg.net.
}

\begin{abstract}
Cystinosis is a rare lysosomal storage disorder caused by loss-of-function mutations of the CTNS gene, encoding cystinosin, a symporter that mediates cystine efflux from lysosomes. Approximately $95 \%$ of patients with cystinosis display renal Fanconi syndrome, short stature, osteopenia, and rickets. In this study, we investigated whether the absence of cystinosin primarily affects bone remodeling activity, apart from the influences of the Fanconi syndrome on bone mineral metabolism. Using micro-computed tomography and histomorphometric and bone serum biomarker analysis, we evaluated the bone phenotype of 1-month-old $\mathrm{Ctns}^{-/-}$knockout (KO) male mice without tubulopathy. An in vitro study was performed to characterize the effects of cystinosin deficiency on osteoblasts and osteoclasts. Micro-computed tomography analysis showed a reduction of trabecular bone volume, bone mineral density, and number and thickness in K0 mice compared with wild-type animals; histomorphometric analysis revealed a reduction of osteoblast and osteoclast parameters in tibiae of cystinotic mice. Decreased levels of serum procollagen type 1 amino-terminal propeptide and tartrate-resistant acid phosphatase in $\mathrm{KO}$ mice confirmed reduced bone remodeling activity. In vitro experiments showed an impairment of $\mathrm{Ctns}^{-/-}$osteoblasts and osteoclasts. In conclusion, cystinosin deficiency primarily affects bone cells, leading to a bone loss phenotype of $\mathrm{KO}$ mice, independent from renal failure. (Am J Pathol 2019, 189: 1053-1064; https://doi.org/10.1016/j.ajpath.2019.01.015)
\end{abstract}

Cystinosis is a rare autosomal recessive disease caused by loss-of-function mutations of the CTNS gene, which encodes the cystinosin symporter. ${ }^{1}$ Cystinosin is an integral lysosomal membrane protein responsible for protoncoupled cystine export from the lysosomal lumen to the cytosol. $^{2,3}$ Loss of cystinosin-dependent transport activity induces cystine accumulation in lysosomes, leading to crystal formation and cellular damage. ${ }^{4}$ Cystinosis is a monogenic disease. According to the severity of CTNS mutations, three major clinical presentations have been recognized (namely, infantile or nephropathic, juvenile, and ocular nonnephropathic cystinosis). ${ }^{5,6}$ Approximately $95 \%$ of patients have the nephropathic form, which manifests during the first year of life with renal Fanconi syndrome, leading to excessive wasting of electrolytes and metabolites in the urine, growth retardation, osteopenia, and rickets. ${ }^{7,8}$ Infants and young children with nephropathic cystinosis display skeletal abnormalities, including genu valgum or varum, metaphyseal widening, rachitic rosary, frontal bossing, poor mobility, bone fractures, increased serum alkaline phosphatase level, hypocalcemia, hypophosphatemia, and hypokalemia. $^{9-11}$ To date, clinical manifestations associated with hypophosphatemic rickets in patients with nephropathic cystinosis have been thought to be mainly caused by phosphate depletion, secondary to renal tubule damage. ${ }^{10,12,13}$ However, bone alterations and decreased mineralization, described in an animal model of cystinosis, were not associated with Fanconi syndrome. ${ }^{14}$ Moreover, mesenchymal stem cells (MSCs) isolated from a patient with nephropathic cystinosis showed a reduced ability to differentiate into

Supported by Cystinosis Research Foundation grant CRFS-2015-006 (A.T. and A.D.F.) and the Italian Ministry of Health Ricerca Corrente grant RC201602G003692 (F.E.).

A.T. and A.D.F. contributed equally to this work as senior authors.

Disclosures: None declared. 
Table 1 List and Sequence of Primers

\begin{tabular}{|c|c|c|}
\hline Gene & Forward primer & Reverse primer \\
\hline Lrp2 & $5^{\prime}$-CAGTGGATTGGGTAGCAGGA-3' & 5'-GCTTGGGGTCAACAACGATA-3' \\
\hline Cbln & $5^{\prime}-$ TCATTGGCCTCAGACATTCC-3' & 5'-CCCAGACCTTCACAAAGCTG-3' \\
\hline Sp7 & 5'-АССTTTCGTCTTCCTGAGCTT-3' & 5'-CTGGCGCATAGGGGTTAAGT-3' \\
\hline Alp & $5^{\prime}-\mathrm{GGACAGGACACACACACACA-3^{ \prime }}$ & $5^{\prime}-\mathrm{CAAACAGGAGAGCCACTTCA-3^{ \prime }}$ \\
\hline Col1a2 & 5'-CCGTGCTTCTCAGAACATCA-3' & $5^{\prime}$-GAGCAGCCATCGACTAGGAC-3' \\
\hline Ctsk & 5'-GTAGCCACGCTTCCTATCCG-3' & $5^{\prime}$-CCTCCAGGTTATGGGCAGAG- $3^{\prime}$ \\
\hline Acp5 & $5^{\prime}$-GAGAACGGTGTGGGCTATGT-3' & 5'-CTGTGGGATCAGTTGGTGTG-3' \\
\hline Gapdh & 5'-GTTCCTACCCCCAATGTGT-3' & $5^{\prime}$-GTGAGGGAGATCCTCAGTG-3' \\
\hline
\end{tabular}

mature osteoblasts in vitro, thus independently from renal dysfunction. ${ }^{15}$ Taken together, these data suggest that other factors contribute to bone disease. To investigate whether skeletal alterations in nephropathic cystinosis are also due to primary bone defects, we have evaluated the effects of cystinosin deficiency in bone cells and the bone phenotype of $\mathrm{Ctns}^{-/-}$mice that have a normal renal phenotype during the first post-natal month of life.

\section{Materials and Methods}

\section{Animals}

Mice were treated according to the NIH's Guide for the Care and Use of Laboratory Animals, Italian Legislative Decree 116/92, and European Economic Community Council Directive 86/609. ${ }^{16}$ C57BL/6 $\mathrm{Ctns}^{-1-}$ mice were previously generated in the laboratory of Dr. Corinne Antignac (INSERM U1163, Paris Descartes University, Paris, France), as described by Nevo et al. ${ }^{17}$

\section{Blood and Urine Analysis}

Urine samples were collected from mice kept in metabolic cages for 24 hours. Urinary creatinine, glucose, albumin, calcium, and phosphate were measured with the use of
HITACHI Cobas C311 (Roche Daignostiics GmbH, Mannheim, Germany). Clara cell protein level was measured using the Immunosorbent Assay kit in accordance with manufacturer's instructions (Biomatik, Wilmington, DE). Blood samples were taken from the submandibular vein and collected in microtainer tubes (BD, Franklin Lakes, NJ) containing gel for serum separation. Creatinine and blood urea nitrogen were measured with the use of HITACHI Cobas C311. Serum calcium and phosphate were evaluated by Siemens ADVIA 1800 Chemistry System (Siemens Healthineers, Erlangen, Germany). Tartrate-resistant acid phosphatase (TRAcP), carboxy-terminal collagen crosslinks, procollagen type 1 amino-terminal propeptide, parathyroid hormone 1-84, C-terminal fibroblast growth factor 23, and 1,25-dihydroxyvitamin D3 were measured by enzyme-linked immunosorbent assay kits, according to the manufacturers' instructions (Biomedical Technologies Inc., Stoughton, MA; and Quidel, San Diego, CA).

\section{Histology}

Kidneys were fixed in $4 \%$ formaldehyde in $0.1 \mathrm{~mol} / \mathrm{L}$ phosphate buffer, $\mathrm{pH}$ 7.2; dehydrated in ethanol; and processed for paraffin embedding. Sections (3 $\mu \mathrm{m}$ thick) were stained for megalin (Abcam, Cambridge, UK) and

Table 2 Urine Chemistry in WT and KO Mice

\begin{tabular}{|c|c|c|c|c|c|c|}
\hline \multirow[b]{2}{*}{ Variable } & \multicolumn{2}{|l|}{1 Month } & \multicolumn{2}{|l|}{3 Months } & \multicolumn{2}{|l|}{6 Months } \\
\hline & WT & KO & WT & KO & WT & KO \\
\hline $\mathrm{CC} 16, \mu \mathrm{g} / \mathrm{g}$ creatinine & $285 \pm 72$ & $350 \pm 54$ & $26 \pm 6$ & $60 \pm 10 * *$ & $20 \pm 6$ & $1166 \pm 751^{*}$ \\
\hline Albumin, $\mathrm{mg} / \mathrm{g}$ creatinine & $20.1 \pm 4.2$ & $13.0 \pm 5.4$ & $4.4 \pm 0.4$ & $4.5 \pm 0.8$ & $17.1 \pm 3.9$ & $15.3 \pm 2.4$ \\
\hline Creatinine, $\mathrm{mg} / \mathrm{dL}$ & $49.7 \pm 4.4$ & $42.8 \pm 9.0$ & $48.5 \pm 3.6$ & $44.5 \pm 6.5$ & $44.0 \pm 4.9$ & $47.3 \pm 3.8$ \\
\hline Glucose, mmol/L & $7.2 \pm 1.0$ & $8.2 \pm 1.7$ & $3.1 \pm 0.2$ & $3.0 \pm 0.8$ & $0.9 \pm 0.3$ & $15.0 \pm 3.7^{* *}$ \\
\hline Calcium, mg/mg creatinine & $0.41 \pm 0.07$ & $0.71 \pm 0.14$ & $0.16 \pm 0.01$ & $0.42 \pm 0.20$ & $0.13 \pm 0.02$ & $0.34 \pm 0.14^{*}$ \\
\hline Phosphate, $\mathrm{mg} / \mathrm{mg}$ creatinine & $3.09 \pm 0.44$ & $3.51 \pm 0.48$ & $3.20 \pm 0.25$ & $2.40 \pm 0.39$ & $2.23 \pm 0.50$ & $2.34 \pm 0.39$ \\
\hline Diuresis, $\mathrm{mL} / 24$ hours & $0.60 \pm 0.10$ & $0.68 \pm 0.14$ & $0.93 \pm 0.16$ & $0.91 \pm 0.11$ & $1.87 \pm 0.36$ & $1.21 \pm 0.14$ \\
\hline
\end{tabular}

Each group is composed of more than seven mice. KO mice were compared with age-matched WT mice for statistical analysis. Values are reported as means \pm SEM. $U$-test was used.

${ }^{*} P<0.05,{ }^{* *} P<0.005$ versus WT mice.

CC16, Clara cell protein; K0, cystinotic; WT, wild type. 
Table 3 Serum Chemistry in WT and KO Mice

\begin{tabular}{|c|c|c|c|c|c|c|}
\hline \multirow[b]{2}{*}{ Variable } & \multicolumn{2}{|l|}{1 Month } & \multicolumn{2}{|l|}{3 Months } & \multicolumn{2}{|l|}{6 Months } \\
\hline & WT & KO & WT & KO & WT & KO \\
\hline BUN, mg/dL & $29.8 \pm 1.5$ & $32.5 \pm 2.4$ & $45.4 \pm 1.4$ & $39.4 \pm 3.1$ & $65.3 \pm 4.9$ & $59.3 \pm 6.8$ \\
\hline Calcium, mg/dL & $9.66 \pm 0.23$ & $10.4 \pm 0.44$ & $9.04 \pm 0.18$ & $9.54 \pm 0.21$ & $9.63 \pm 0.24$ & $9.61 \pm 0.32$ \\
\hline Phosphate, mg/dL & $11.6 \pm 0.7$ & $9.9 \pm 0.6$ & $8.7 \pm 0.7$ & $7.9 \pm 0.3$ & $8.8 \pm 0.2$ & $7.8 \pm 0.4^{*}$ \\
\hline $1,25(\mathrm{OH})_{2}$ Vit. D3, pmol/L & $261 \pm 41$ & $182 \pm 16$ & $332 \pm 58$ & $299 \pm 22$ & $219 \pm 4$ & $259 \pm 30$ \\
\hline
\end{tabular}

Values are reported as means \pm SEM. $U$-test was used.

${ }^{*} P<0.05$ versus WT mice.

1,25(OH $)_{2}$ Vit. D3, 1,25-dihydroxyvitamin D3; BUN, blood urea nitrogen; K0, cystinotic; WT, wild type.

cubilin (Santa Cruz Biotechnology, Dallas, TX) immunohistochemistry. For histologic analysis of calcified tissue, bones were fixed in $4 \%$ formaldehyde in $0.1 \mathrm{~mol} / \mathrm{L}$ phosphate buffer, dehydrated in acetone, and embedded in 2-hydroxyethyl-methacrylate. Histomorphometric measurements were performed on sections ( 2 to $3 \mu \mathrm{m}$ thick) with an interactive image analysis system (NIS-Elements BR 4.50.00; Tokyo, Japan). Nomenclature, symbols, and units of histomorphometric bone parameters were those suggested by the Histomorphometry Nomenclature Committee of the American Society for Bone and Mineral Research. $^{18}$
A

C

WT

1 month

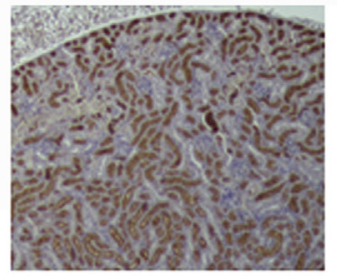

3 months

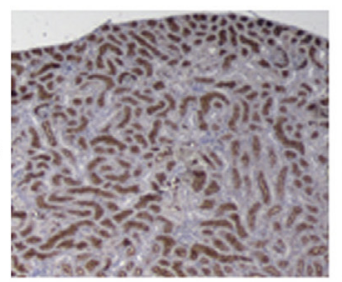

6 months

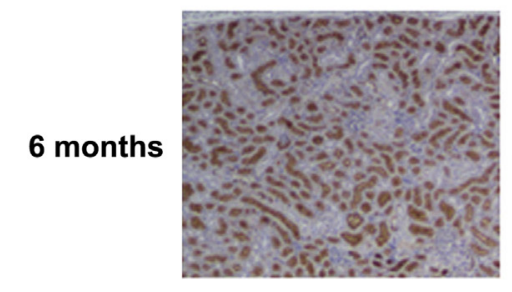

B

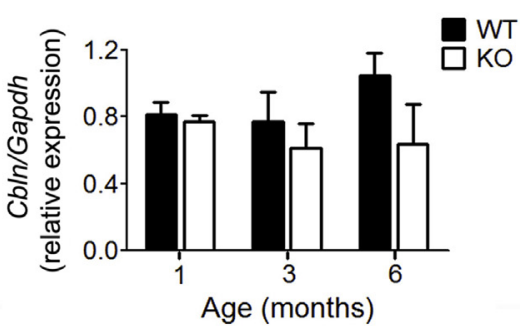

KO
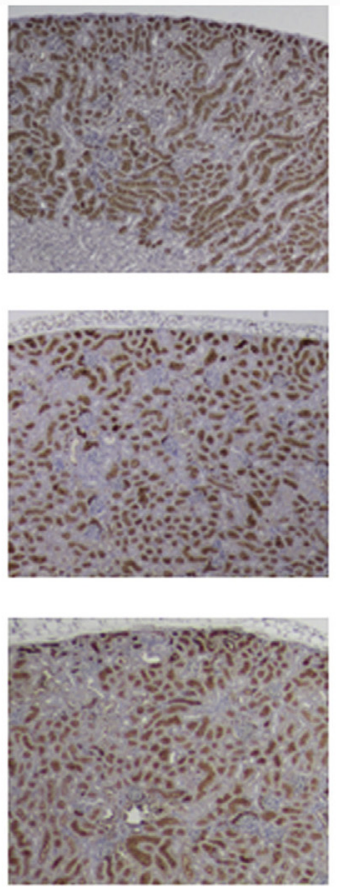

D

1 month

3 months

6 months
Figure 1 Megalin and cubilin expression in kidneys of wild-type (WT) and cystinotic (KO) mice. A and B: Realtime RT-PCR for megalin (Lrp2; A) and cubilin (Cbln; B) was performed on cDNA obtained from mRNA extracted from kidney of WT (black bars) and KO (white bars) mice at 1, 3, and 6 months of age. Values are normalized versus the housekeeping gene Gapdh. C and D: Immunohistochemistry in paraffin-embedded renal sections ( 3 $\mu \mathrm{m}$ thick) of 1-, 3-, and 6-month-old WT and KO mice. C and D: Staining for megalin (C) and cubilin (D). Data are expressed as means \pm SEM. ${ }^{*} P<0.05$ versus WT animals. Original magnification, $\times 10$ (C and $\mathbf{D})$.
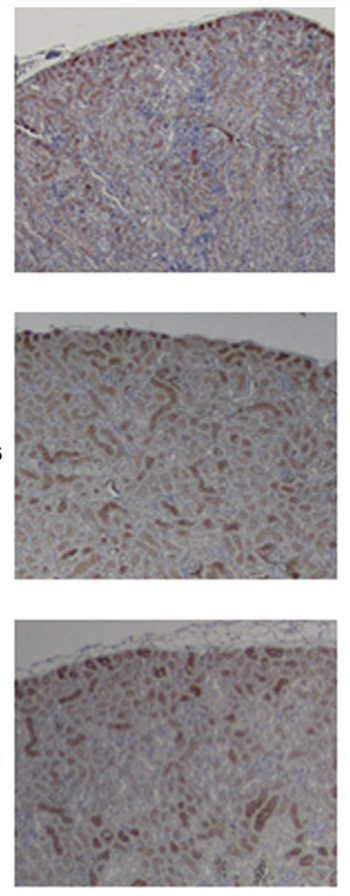
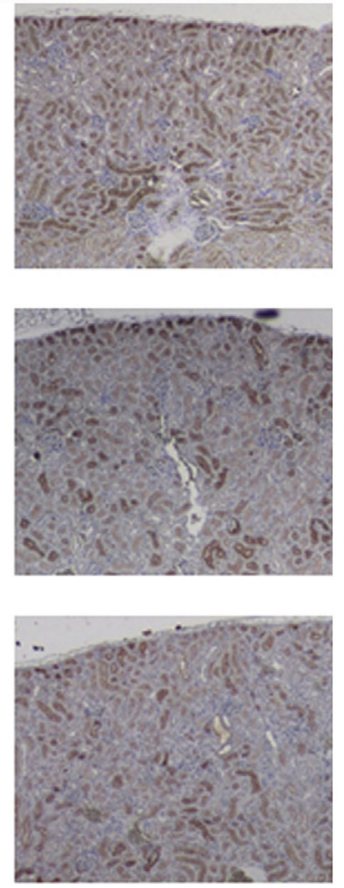


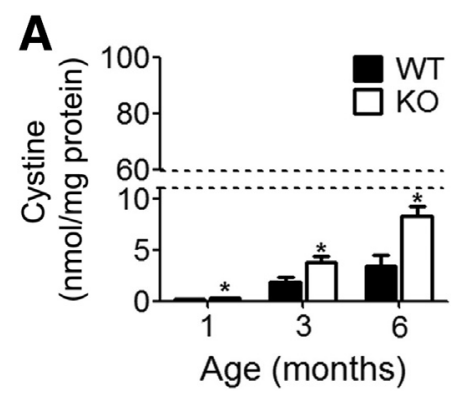

Micro-Computed Tomography

Femurs were excised and cleaned to remove soft tissues. A high-resolution desktop microtomographic imaging system ( $\mu$ CT40; Scanco Medical AG, Brüttisellen, Switzerland) was used to assess trabecular bone microarchitecture and cortical bone morphology in the distal femoral metaphysis and middiaphysis, respectively. Scans were acquired using a $10-\mu \mathrm{m}^{3}$ isotropic voxel size, $70-\mathrm{kV}$ peak $\mathrm{X}$-ray tube intensity, 114-mA X-ray tube current, and 200-millisecond integration time; and they were subjected to gaussian filtration and segmentation. Image acquisition and analysis protocols adhered to guidelines for the use of micro-computed tomography for the assessment of bone microstructure in rodents. ${ }^{19}$ Trabecular bone was evaluated in a $1500-\mu \mathrm{m}-$ long region (150 transverse slices) beginning $200 \mu \mathrm{m}$ above the peak of the distal growth plate and extending proximally. Trabecular bone was segmented from soft tissue using a threshold of $388 \mathrm{mg}$ hydroxyapatite $/ \mathrm{cm}^{3}$, and the Scanco Evaluation program Trabecular Morphology script (Scanco Medical AG) was used to measure the trabecular bone volume fraction (bone volume/total volume; $\%)$, trabecular thickness $(\mu \mathrm{m})$, trabecular number $(1 / \mathrm{mm})$, trabecular separation $(\mu \mathrm{m})$, and trabecular bone mineral density $\left(\mathrm{mg}\right.$ hydroxyapatite $\left./ \mathrm{cm}^{3}\right)$. Cortical bone architecture was evaluated in a 500- $\mu \mathrm{m}-$ long region (50 transverse slices) at the femoral middiaphysis. Cortical bone was segmented using a threshold of $700 \mathrm{mg}$ hydroxyapatite $/ \mathrm{cm}^{3}$ and then evaluated using the Scanco Mid-Shaft Evaluation script (Scanco Medical AG) to measure total cross-sectional area $\left(\mathrm{mm}^{2}\right)$, cortical bone area $\left(\mathrm{mm}^{2}\right)$, medullary area $\left(\mathrm{mm}^{2}\right)$, cortical bone area fraction (cortical bone area/total area; \%), cortical thickness $(\mu \mathrm{m})$, as well as the maximum, minimum, and polar moments of inertia $\left(\mathrm{mm}^{4}\right)$.

\section{Cystine Analysis}

For cystine content measurements, kidney, long bones (ulna and radius), osteoblasts, and osteoclasts were sonicated in the presence of $10 \mathrm{mmol} / \mathrm{L} \mathrm{N}$-ethylmaleimide. The protein fraction was precipitated by the addition of $10 \% 5$-sulfosalicylic acid and measured using the Pierce bicinchoninic acid protein assay (Thermo Fisher Scientific, Carlsbad, CA). Cystine levels were measured by high-performance liquid chromatography, as described by Pastore et al. ${ }^{20}$

\section{Murine Osteoblast Primary Cultures}

\section{Differentiation of Bone Marrow MSCs into 0steoblasts}

MSCs were isolated from bone marrow of wild-type (WT) mice. After reaching $90 \%$ confluence, cells were trypsinized and seeded in 12-well plates at a density of $8 \times 10^{4}$ cells/ well. Medium supplemented with $10 \%$ fetal bovine serum (FBS), $50 \mu \mathrm{g} / \mathrm{mL}$ L-ascorbic acid, and $10 \mathrm{mmol} / \mathrm{L} \beta$-glycerol phosphate (Sigma-Aldrich, St. Louis, MO) was then added after 2 days. Medium was changed every 3 to 4 days; and after 1,2, and 3 weeks of culture, gene expression analysis was performed. To confirm the osteogenic differentiation, alkaline phosphatase staining was evaluated by Alkaline Phosphatase Activity Kit No. 86C (Sigma-Aldrich).

Table 4 Microarchitectural Parameters of Femurs from WT and KO Mice

\begin{tabular}{|c|c|c|c|c|c|c|}
\hline \multirow[b]{2}{*}{ Variable } & \multicolumn{2}{|l|}{1 Month } & \multicolumn{2}{|l|}{3 Months } & \multicolumn{2}{|l|}{6 Months } \\
\hline & WT & KO & WT & KO & WT & KO \\
\hline BMD, mg hydroxyapatite $/ \mathrm{cm}^{3}$ & $189 \pm 9$ & $163 \pm 8^{* *}$ & $230 \pm 22$ & $233 \pm 36$ & $194 \pm 35$ & $182 \pm 22$ \\
\hline Tb.N, 1/mm & $4.50 \pm 0.26$ & $3.56 \pm 0.42 * *$ & $5.11 \pm 0.20$ & $5.23 \pm 0.53$ & $3.73 \pm 0.35$ & $3.66 \pm 0.32$ \\
\hline Tb.Th, $\mu \mathrm{m}$ & $43.60 \pm 0.55$ & $41.00 \pm 0.82^{* * *}$ & $52.00 \pm 2.50$ & $52.10 \pm 2.34$ & $57.40 \pm 4.54$ & $54.00 \pm 3.02$ \\
\hline Tb.Sp, $\mu \mathrm{m}$ & $230 \pm 10$ & $300 \pm 40^{* *}$ & $188 \pm 9$ & $186 \pm 23$ & $262 \pm 27$ & $268 \pm 31$ \\
\hline
\end{tabular}

Each group is composed of more than seven mice. Values are reported as means \pm SEM. $U$-test was used.

${ }^{* *} P<0.005,{ }^{* * *} P<0.001$ versus WT mice.

BMD, bone mineral density; BV, bone volume; Conn.D, connectivity density; K0, cystinotic; SMI, structural model index; Tb.N, trabecular number; Tb.Sp, trabecular separation; Tb.Th, trabecular thickness; TV, total volume; WT, wild type. 
A

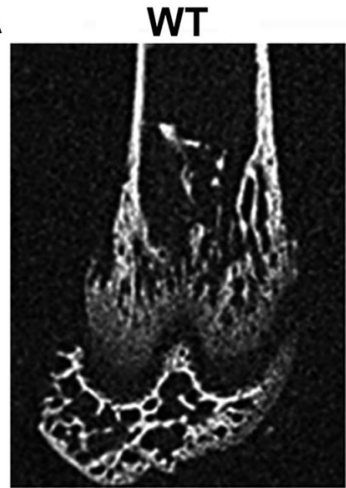

B

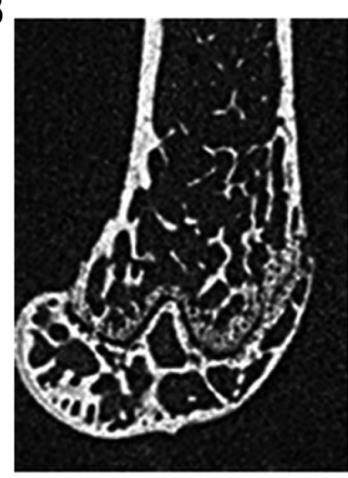

C

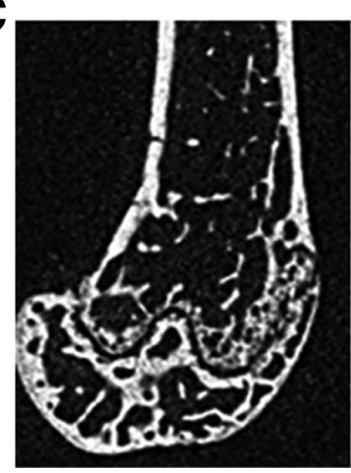

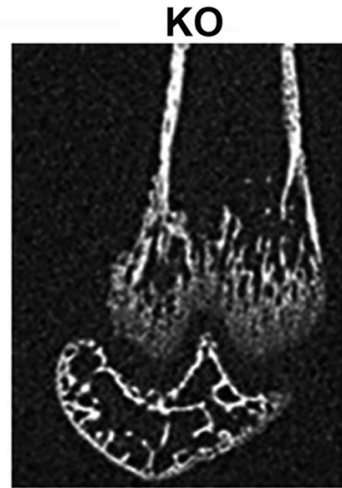
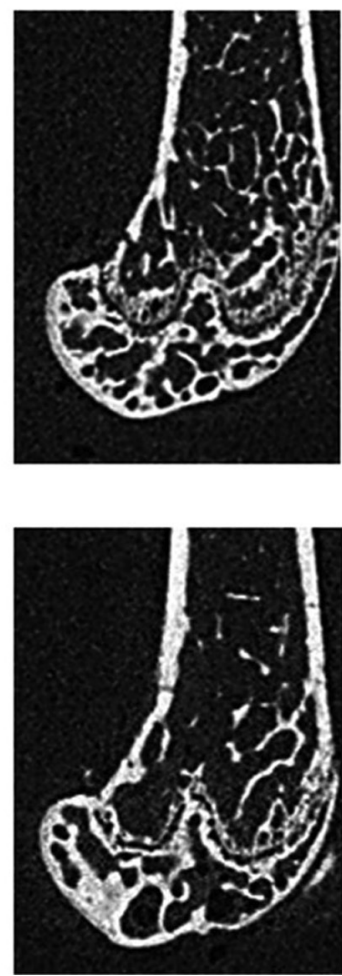

Figure 3 Micro-computed tomography (microCT) analysis. Representative microCT images of distal femurs of wild-type (WT) and cystinotic (KO) mice at 1 (A), 3 (B), and 6 (C) months of age.

\section{Isolation of Osteoblasts from Calvaria}

Calvaria were digested with Clostridium histolyticum collagenase and trypsin at $37^{\circ} \mathrm{C}$ three times for 15,30 , and 45 minutes, with gentle agitation. The isolated cells were grown in Dulbecco's modified Eagle's medium (DMEM) plus $10 \%$ FBS, trypsinized, and plated according to the experimental protocol. Alkaline phosphatase activity was evaluated, as described in Differentiation of Bone Marrow MSCs into Osteoblasts.

\section{Mineralization Assay}

Osteoblasts isolated from calvaria were cultured in DMEM plus $10 \%$ FBS, $10 \mathrm{mmol} / \mathrm{L} \beta$-glycerophosphate, and $50 \mu \mathrm{g} / \mathrm{mL}$ ascorbic acid to induce mineralization. After 3 weeks, von
Kossa staining was performed to evaluate the mineralized area by an image analysis system (NIS-Elements BR 4.50.00).

\section{Murine Osteoclast Primary Cultures}

\section{Osteoclast Precursors}

Bone marrow of the long bones of mice was flushed out and diluted in Hanks' balanced salt solution. Cells were stratified over an equal volume of Histopaque 1077 (SigmaAldrich). After a centrifugation at $400 \times g$ for 30 minutes, the interface layer was isolated, washed twice in Hanks' balanced salt solution $(250 \times g, 10$ minutes), resuspended in DMEM containing $10 \%$ FBS, and fixed in $4 \%$ formaldehyde after 3 hours. TRAcP activity was detected histochemically by kit No. 85 (Sigma-Aldrich).

\section{Osteoclast Culture}

For osteoclastogenesis, osteoclast precursors were cultured in DMEM plus 10\% FBS supplemented with $50 \mathrm{ng} / \mathrm{mL}$ recombinant murine macrophage colony-stimulating factor and $120 \mathrm{ng} / \mathrm{mL}$ recombinant murine receptor activator of $\mathrm{NF}-\kappa \mathrm{B}$ ligand for 7 days. Osteoclasts were detected by histochemical staining for TRAcP.

\section{Resorption Assay}

Osteoclast precursors were differentiated on bovine bone slices in DMEM plus 10\% FBS supplemented with $50 \mathrm{ng} / \mathrm{mL}$ macrophage colony-stimulating factor and 120 $\mathrm{ng} / \mathrm{mL}$ receptor activator of NF- $\kappa \mathrm{B}$ ligand. Resorption pit area was measured by image analysis system (NIS-Elements BR 4.50.00) and normalized for the osteoclast number.

\section{Real-Time RT-PCR}

Total RNA was extracted using the TRIzol procedure. RNA (1 $\mu \mathrm{g})$ was reverse transcribed using the Moloney murine leukemia virus reverse transcriptase. For real-time PCR, $0.1 \mu \mathrm{g}$ cDNA, the Brilliant SYBR Green QPCR (Bioline, London, UK) master mix, and primers indicated in Table 1 were used.

\section{Statistical Analysis}

Data were expressed as means \pm SEM of at least three independent experiments or seven animals per group. Values were compared by unpaired $t$-test if data pass normality tests (Kolmogorov-Smirnov or Shapiro-Wilk test) or by nonparametric $U$-test, as appropriate. A result with $P<0.05$ was considered statistically significant. Analyses were performed through GraphPad Prism software version 6 (GraphPad Software, San Diego, CA).

\section{Results}

\section{Kidney Phenotype}

To study the primary role of bone in the development of osteopenia and rickets in the nephropathic cystinosis, skeletal 
Table 5 Microarchitectural Parameters of Middiaphysis of Femurs from WT and KO Mice

\begin{tabular}{|c|c|c|c|c|c|c|}
\hline \multirow[b]{2}{*}{ Variable } & \multicolumn{2}{|l|}{1 Month } & \multicolumn{2}{|l|}{3 Months } & \multicolumn{2}{|l|}{6 Months } \\
\hline & WT & KO & WT & KO & WT & KO \\
\hline Tt.Ar, mm ${ }^{2}$ & $1.58 \pm 0.16$ & $1.43 \pm 0.13$ & $1.85 \pm 0.15$ & $1.91 \pm 0.12$ & $2.06 \pm 0.19$ & $1.85 \pm 0.16^{*}$ \\
\hline Ct.Ar, mm ${ }^{2}$ & $0.40 \pm 0.03$ & $0.38 \pm 0.02$ & $0.80 \pm 0.05$ & $0.81 \pm 0.05$ & $0.86 \pm 0.07$ & $0.77 \pm 0.04^{* *}$ \\
\hline Ma.A, $\mathrm{mm}^{2}$ & $1.17 \pm 0.13$ & $1.05 \pm 0.11$ & $1.04 \pm 0.11$ & $1.09 \pm 0.07$ & $1.20 \pm 0.15$ & $1.07 \pm 0.12$ \\
\hline Ct.Ar/Tt.Ar, \% & $25.7 \pm 1.7$ & $26.6 \pm 1.5$ & $43.6 \pm 1.7$ & $42.6 \pm 0.7$ & $41.8 \pm 3.3$ & $42.1 \pm 1.1$ \\
\hline Ct.Th, $\mu \mathrm{m}$ & $91.0 \pm 2.0$ & $89.4 \pm 1.2$ & $179.7 \pm 2.6$ & $175.1 \pm 2.3$ & $178.6 \pm 4.8$ & $170.0 \pm 1.4^{*}$ \\
\hline Imax, $\mathrm{mm}^{4}$ & $0.11 \pm 0.02$ & $0.09 \pm 0.02$ & $0.26 \pm 0.04$ & $0.28 \pm 0.04$ & $0.31 \pm 0.05$ & $0.26 \pm 0.04^{*}$ \\
\hline Imin, $\mathrm{mm}^{4}$ & $0.07 \pm 0.01$ & $0.06 \pm 0.01$ & $0.13 \pm 0.02$ & $1.75 \pm 0.30$ & $0.16 \pm 0.03$ & $0.12 \pm 0.02^{*}$ \\
\hline pMOI, $\mathrm{mm}^{4}$ & $0.18 \pm 0.03$ & $0.15 \pm 0.02$ & $0.39 \pm 0.06$ & $0.41 \pm 0.05$ & $0.47 \pm 0.08$ & $0.38 \pm 0.06^{*}$ \\
\hline
\end{tabular}

Values are reported as means \pm SEM. $U$-test was used.

${ }^{*} P<0.05,{ }^{*} P<0.005$ versus WT mice.

Ct.Ar, cortical bone area; Ct.Th, cortical thickness; Imax, maximum moment of inertia; Imin, minimum moment of inertia; K0, cystinotic; Ma.A, medullary area; pMOI, polar moment of inertia; Tt.Ar, total area; WT, wild type.

alterations of $\mathrm{Ctns}^{-1-} \mathrm{C} 57 \mathrm{BL} / 6$ mice [knockout (KO) mice] were analyzed. Because cystinotic mice develop Fanconi syndrome between 2 and 9 months of age, ${ }^{17}$ the renal function was studied in male animals at different ages (1, 3, and 6 months). The first sign of renal damage was observed at 3 months of age and was characterized by urine loss of low-molecular-weight Clara cell protein. Glycosuria, normocalcemic hypercalciuria, and hypophosphatemia developed at the age of 6 months, whereas no changes of blood urea nitrogen, serum creatinine, diuresis, urinary phosphate, and albumin were revealed (Tables 2 and 3). 1,25-Dihydroxyvitamin D3 levels did not show any alterations between WT and KO animals at different ages (Table 3).

Moreover, histologic analysis of kidney biopsies isolated from 1-, 3-, and 6-month-old mice did not reveal the focal atrophy of juxtaglomerular proximal tubules (swan neck lesions), typical feature of nephropathic cystinosis (data not shown). In addition, the expression of two receptors (megalin and cubilin), whose decrease is a sign of tubular dysfunction, was evaluated. At 1 to 3 months of age, $\mathrm{KO}$ mice did not show any differences in the expression of these receptors; reduced mRNA levels of megalin (Lrp2) and a trend of decrease of cubilin were revealed in 6-month-old
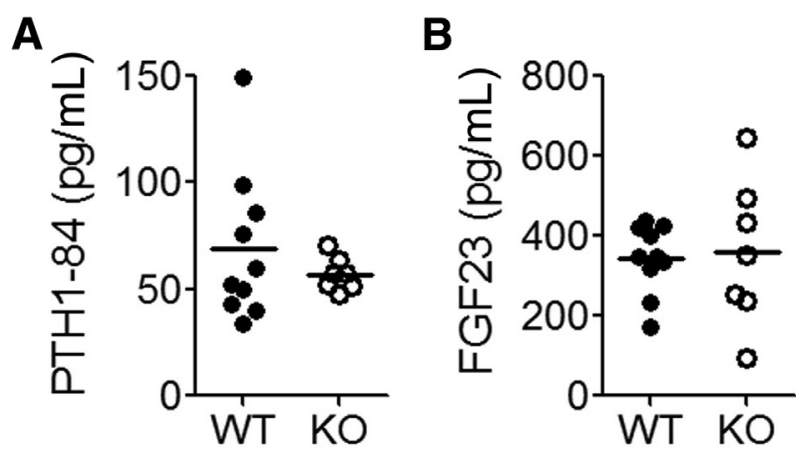

Figure 4 Parathyroid hormone (PTH) and fibroblast growth factor (FGF) 23 levels in 1-month-old mice. Enzyme-linked immunosorbent assay for PTH1-84 (A) and FGF23 (B) in plasma samples from wild-type (WT) and cystinotic (KO) mice. Data are expressed as means \pm SEM.
$\mathrm{Ctns}^{-/-}$kidneys (Figure 1, A and B). However, immunohistochemistry analysis did not display relevant alterations of the protein expression and localization of these two receptors (Figure 1, C and D).

\section{Cystine Content}

Cystinotic tissues are characterized by intralysosomal cystine accumulation. Cystine content was evaluated after animal sacrifice in kidneys and bones by high-performance liquid chromatography. Cystine accumulated progressively in kidney (Figure 2A) and long bones (ulna and radius) (Figure 2B) of $\mathrm{KO}$ animals.

\section{Bone Phenotype in $\mathrm{Ctns}^{-/-}$Mice}

Bone phenotype was analyzed in 1-, 3-, and 6-month-old animals. Micro-computed tomography showed a significant decrease in trabecular bone in the distal metaphysis of the femurs in 1-month-old cystinotic mice compared with wild-type animals (Table 4 and Figure 3A). Concordantly, bone mineral density, bone volume/total volume, trabecular number, and trabecular thickness were significantly decreased, and trabecular separation was increased (Table 4, Figure 3A, and Supplemental Figure S1A). No significant differences were observed at later ages (Table 4 and Figure 3, B and C). Cortical bone was similar between WT and $\mathrm{KO}$ animals at 1 and 3 months and displayed significant reduction at 6 months (Table 5). Indeed, 6-month-old $\mathrm{KO}$ mice showed an obvious thinning of the collar micro-computed tomography parameters with a reduction of maximum, minimum, and polar moments of inertia (Table 5).

High-power radiographs of tibia isolated from 1-month-old mice confirmed an osteopenic phenotype in growing cystinotic bones in the absence of renal damage (Supplemental Figure S1B).

Finally, parathyroid hormone and fibroblast growth factor 23 regulating bone and kidney axis were evaluated. No 
A
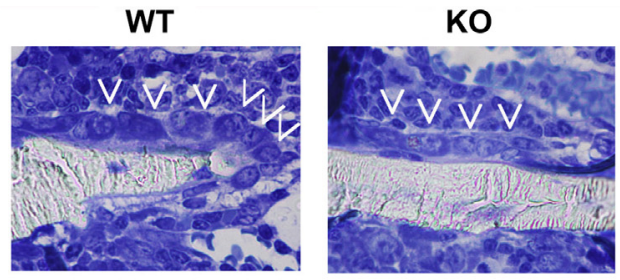

B
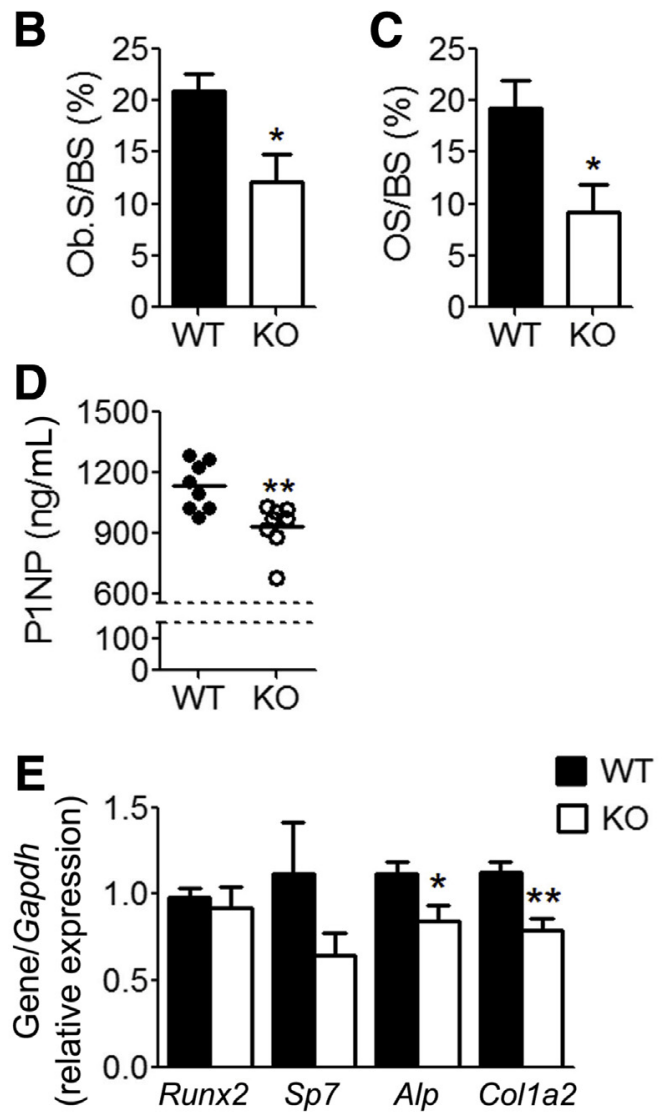

Figure 5 In vivo effects of cystinosin deficiency on osteoblasts in 1-month-old mice. A: Representative images of toluidine blue-stained semithin sections of wild-type (WT) and cystinotic (KO) proximal spongiosa lined by cuboidal osteoblasts (arrowheads). B and C: Histomorphometric evaluation of osteoblast surface (Ob.S) and osteoid surface (OS) in proximal spongiosa tibia of WT (black bars) and KO (white bars) mice. D: Enzyme-linked immunosorbent assay for procollagen type 1 amino-terminal propeptide (P1NP) in serum collected from WT and K0 mice. E: Gene expression of osteoblast markers (Runx2, Sp7, Alp, and Col1a2) measured by real-time RT-PCR analysis on mRNA extracted from femurs of WT and KO mice. Values are normalized versus the housekeeping gene Gapdh. Data are expressed as means \pm SEM $(\mathbf{B}-\mathbf{E}){ }^{*} P<0.05,{ }^{*} P<0.005$ versus wild-type animals. Original magnification, $\times 20(\mathbf{A})$. BS, bone surface.

statistically significant differences were observed between 1-month-old wild-type and cystinotic mice (Figure 4).

\section{1-Month-Old $\mathrm{Ctns}^{-/-}$Mice Display Decreased Osteoblast Activity}

A semithin section of 1-month-old tibiae stained with toluidine blue showed reduced surface occupied by osteoblasts, which were also reduced in number, in $\mathrm{KO}$ compared with WT animals (Figure 5A). Cystinotic osteoblasts also presented with scarce osteoid tissue (Figure 5A). This was confirmed by histomorphometric analyses (Figures 5, B and C) and by lower serum levels of the bone formation marker procollagen type 1 amino-terminal propeptide (WT, $1130.0 \pm 120.1 \mathrm{ng} / \mathrm{mL}$; KO, $931.6 \pm 114.6$ $\mathrm{ng} / \mathrm{mL} ; P=0.004$ ) (Figure 5D). Moreover, reduced mRNA levels of the mature osteoblast markers alkaline phosphatase $(\mathrm{Alp})$ and type I collagen (Colla2) (Figure 5E) were observed in $\mathrm{KO}$ femur samples. Conversely, no differences were revealed in the expression of the bone differentiation markers Runx2 (runt-related transcription factor 2) and $S p 7$ (osterix) (Figure 5E).

To evaluate if these alterations were directly caused by cystinosin deficiency in the osteoblast lineage, the expression of cystinosin was first evaluated in cultures of wild-type MSCs induced to differentiate into osteoblasts. The expression of cystinosin increased during osteoblast differentiation (Figure 6A). Further analyses showed that osteoblast cultures from $\mathrm{Ctns}^{-1-}$ mice have increased cystine content (Figure 6B) and a decreased number of alkaline phosphatase-positive cells (Figure 6, C and D). The expression of differentiation and activity markers was evaluated by quantitative PCR, and a reduced expression of Runx2, Sp7, Alp, and Colla2 genes was observed (Figure 6E). Moreover, in vitro mineralization assays revealed reduced ability to release mineralized nodules of cystinotic osteoblasts compared with wild-type cells (Figure 6, F and G).

\section{1-Month-Old Ctns $^{-/-}$Mice Display Reduced Osteoclastogenesis}

To evaluate the involvement of osteoclasts in the osteopenic phenotype observed in KO animals, semithin sections of tibiae from $\mathrm{Ctns}^{-/-}$mice were stained for the osteoclast-specific marker TRAcP. A reduced number of osteoclasts lining the trabecular bone of the proximal spongiosa was observed in KO mice (Figure 7A). This was confirmed by histomorphometric analyses showing a reduction in total osteoclast number (WT, $16.8 \pm 4.2 \mathrm{~N} /$ $\mathrm{mm}^{2} ; \mathrm{KO}, 7.7 \pm 6.1 \mathrm{~N} / \mathrm{mm}^{2} ; P=0.04$ ) and surface (WT, $22.5 \% \pm 6.6 \%$; KO, $12.9 \% \pm 4.9 \% ; P=0.04)$ per bone surface (Figure 7, B and C). Reduction of osteoclastogenesis was further confirmed by decreased TRAcP serum levels (Figure 7D). The measurement of the bone resorption marker carboxy-terminal collagen cross-links did not reveal any statistically significant alterations (WT, $36.0 \pm 9.5 \mathrm{ng} / \mathrm{mL} ; \mathrm{KO}, 30.6 \pm 3.4 \mathrm{ng} / \mathrm{mL} ; P=0.16$ ). Finally, these findings were also supported by quantitative PCR analysis showing reduced expression of osteoclastspecific genes, including receptor activator of NF- $\kappa \mathrm{B}$ (Rank) and matrix metallopeptidase 9 (Mmp9) in 1month-old KO femurs. No differences were revealed for cathepsin $\mathrm{K}(C t s k)$ and acid phosphatase 5 tartrate-resistant (Acp5) expression (Figure 7E). 


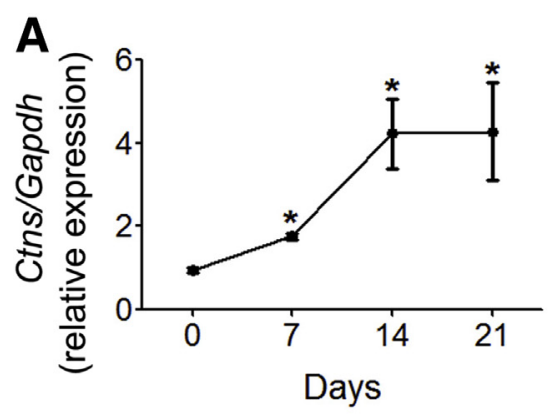

B

D

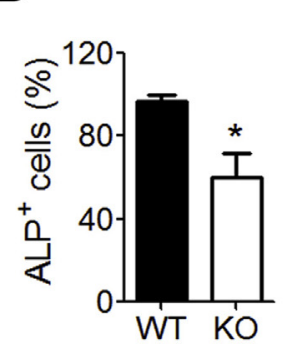

$\mathbf{F}$

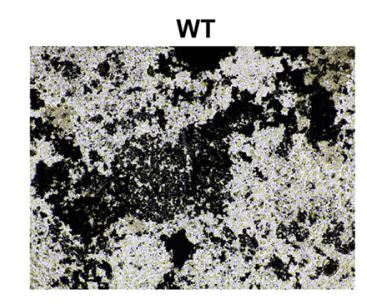

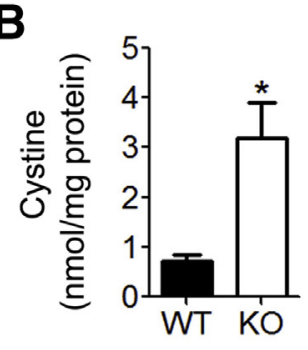

C
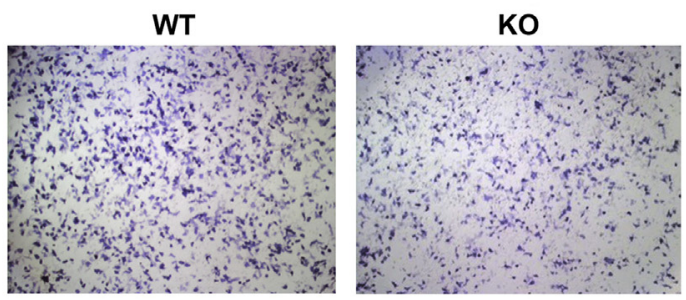

Figure 6 In vitro osteoblast analysis. A: Realtime RT-PCR analysis for cystinosin (Ctns) in wildtype (WT) stromal mesenchymal stem cells (MSCs; time 0 ) and MSCs stimulated to differentiate in osteoblasts for 7, 14, and 21 days. Ctns Values are normalized versus the housekeeping gene Gapdh. B: High-performance liquid chromatography measurement of cystine levels in osteoblasts isolated from WT (black bars) and cystinotic (KO; white bars) mice. C: In vitro osteoblasts isolated from skull bone of WT and KO mice were monitored by alkaline phosphatase (ALP) staining. D: Quantitative expression of ALP-positive cells in WT and KO cultures. Results are reported as percentage versus WT osteoblasts. E: Real-time RT-PCR expression analysis on RNA extracted from WT and cystinotic osteoblasts for Runx2, Sp7, Alp, and Col1a2. Values are normalized versus the housekeeping gene Gapdh. F: Osteoblasts isolated from WT and KO mice were induced to form mineralized nodules and monitored by von Kossa staining. G: Quantitative analysis of mineralized area in WT and K0 cultures. Values are reported as percentage versus WT osteoblast activity. Data are expressed as means \pm SEM (A, B, D, E, and $\mathbf{G}) .{ }^{*} P<0.05$ versus WT cells. Original magnifications: $\times 4(C) ; \times 10(\mathbf{F})$.

To evaluate if these alterations were directly caused by cystinosin deficiency in the osteoclast lineage, the expression of cystinosin was studied in wild-type bone marrow macrophages, osteoclast precursors, and mature cells. A progressive increase of the Ctns gene expression was observed during osteoclastogenesis (Figure 8A). After confirming accumulation of lysosomal cystine in $\mathrm{KO}$ osteoclasts (Figure 8B), the effects of cystinosin deficiency were studied on osteoclast differentiation. The initial number of TRAcP-positive mononuclear precursors was similar in wild-type and cystinotic cultures (Figure 8C). After differentiation, a lower number of mature osteoclasts was observed in $\mathrm{Ctns}^{-1-}$ cultures compared with wild-type cells (Figure 8, D and E). These results were further confirmed by lower Acp5 expression in $\mathrm{KO}$ cultures compared with wild-type cells (Figure $8 \mathrm{~F}$ ). Furthermore, reduced ability to resorb bone was revealed in $\mathrm{KO}$ osteoclasts (Figure 8, $\mathrm{G}$ and $\mathrm{H}$ ).

\section{Discussion}

Bone complications are well known to physicians who manage patients with nephropathic cystinosis and may have substantial repercussion on linear growth and quality of life. ${ }^{21}$ In patients with chronic renal failure, bone metabolism is impaired by complex interactions between kidneys, bone, and parathyroid glands that are primarily mediated by parathyroid hormone, vitamin $\mathrm{D}$, and fibroblast growth factor 23, resulting in chronic kidney disease-mineral bone disorder. Skeletal defects in cystinosis have been attributed to the Fanconi syndrome, which causes metabolic acidosis, urinary leak of phosphate, impaired 1- $\alpha$ hydroxylation of vitamin D3, and loss of lowmolecular-weight proteins. ${ }^{22}$ High urinary loss of vitamin D3 binding protein may aggravate vitamin D3 deficiency. ${ }^{7}$ In addition, urinary copper wasting has also been proposed as a potential factor contributing to bone lesions in cystinosis because copper is an essential cofactor promoting collagen lysine hydroxylation in bones. ${ }^{23,24}$

Cysteamine has represented a major advance in the cystine-depleting treatment of cystinosis. ${ }^{25,26}$ This drug reacts with cystine, generating mixed disulfides, which can exit the lysosome through other membrane transporters. ${ }^{27,28}$ However, recent data suggest that cysteamine may be toxic at high concentrations, probably impairing 
A
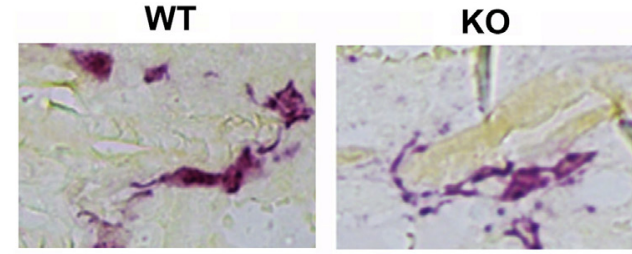

B

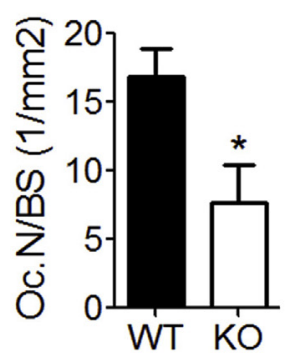

D

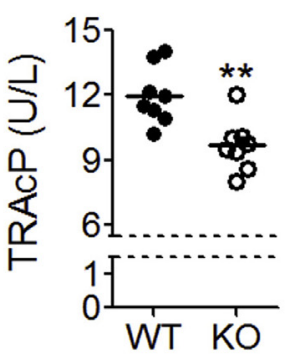

E

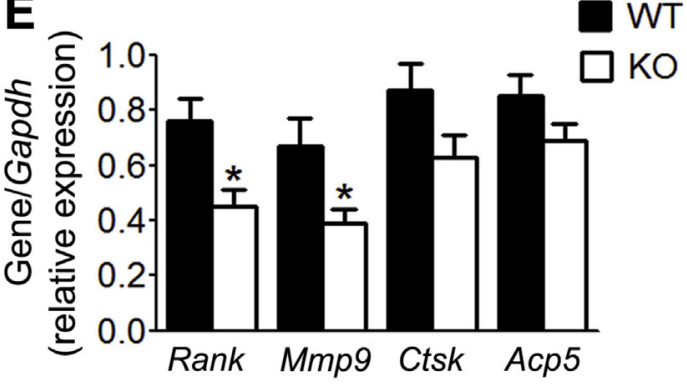

Figure 7 In vivo effects of cystinosin deficiency on osteoclasts in 1-month-old mice. A: Histochemical detection of the osteoclast-specific marker tartrate-resistant acid phosphatase (TRACP) in the semithin sections of proximal spongiosa from wild-type (WT) and cystinotic (KO) tibiae. B and C: Histomorphometric analysis of osteoclast number (Oc.N) and osteoclast surface (0c.S) per bone surface (BS) in WT (black bars) and K0 (white bars) mice. D: Enzyme-linked immunosorbent assay for TRAcP in serum collected from WT and KO mice. E: Real-time RT-PCR expression analysis on RNA extracted from femurs using primer pairs and conditions specific for Rank, Mmp9, Ctsk, and Acp5. Values are normalized versus the housekeeping gene Gapdh. Data are expressed as means \pm SEM (B-E). ${ }^{*} P<0.05,{ }^{* *} P<0.005$ versus WT animals. Original magnification, $\times 20(A)$.

collagen cross-linking; this effect may be amplified by copper deficiency. ${ }^{23}$ Patients with cysteamine toxicity develop skin lesions secondary to angioendotheliomatosis and in some cases develop abrupt bone deformities that can be confused with rickets. ${ }^{23}$ In theory, these patients could represent the tip of the iceberg, and subtle bone defects secondary to cysteamine toxicity may contribute to bone lesions in many more patients with nephropathic cystinosis.
In this view, high doses of cysteamine have been shown in vitro to inhibit osteoblast differentiation and mineralization. ${ }^{29}$

Finally, bone lesions in nephropathic cystinosis may also be caused by a primary defect of bone cells. This was strongly suggested by observations made in the first reported mouse model of cystinosis that developed osteoporosis and rickets-like lesions in the absence of renal failure and phosphate leak. ${ }^{14}$ This hypothesis is further supported by the observation of impaired osteogenic differentiation of MSCs isolated from bone marrow of a cystinotic patient. ${ }^{15}$ This defect was reversed by in vitro treatment with cysteamine. ${ }^{15}$

Herein, it was first confirmed that cystinosin is expressed in bone and that cystine accumulates at high concentrations in this tissue. Animals were analyzed during the first 6 months of life. Differences in trabecular bone between mutated and wild-type animals were evident in the first month of life and disappeared progressively at later ages. Conversely, defects in cortical bone appeared at 6 months of age and could be associated with progressive cystine accumulation and the onset of kidney dysfunction. To confirm the first hypothesis, the effect of cysteamine should be tested, which was beyond the scope of the present study. In the clinical setting, patients who are well treated with cysteamine grow better, ${ }^{30}$ supporting the hypothesis that cystine accumulation in bones has a deleterious effect.

Similar to 6-month-old $\mathrm{Ctns}^{-1-}$ animals, human subjects with chronic kidney failure have lower cortical density and higher cortical porosity in their long bones, without significant modification of bone trabecular parameters. ${ }^{31}$ Hypothetically, incipient renal disease at 6 months may explain, at least in part, cortical defects observed at this age in $\mathrm{Ctns}^{-1-}$ mice; indeed, cortical bone loss could be due to hyperparathyroidism frequently observed in chronic kidney disease patients. ${ }^{31}$ Accordingly, cystinotic teenagers and young adults with Fanconi syndrome display significant cortical impairment. ${ }^{32}$

Bone growth requires the sequential activation of bone cell maturation processes and constant remodeling. Children with nephropathic cystinosis display more growth retardation, compared with their classmates with the same degree of renal failure. ${ }^{33}$ This clinical observation further supports the hypothesis of an intrinsic bone defect in cystinosis, which is strongly corroborated by our results in 1-month-old cystinotic mice. At this age, which corresponds to maximal murine growth and bone formation rates, ${ }^{33,34}$ animals had no signs of renal failure or evidence of Fanconi syndrome. Yet, a significant reduction in trabecular bone volume that was not associated with differences in calciuria, phosphaturia, vitamin D3, parathyroid hormone, and fibroblast growth factor 23, compared with control animals, was observed. Histomorphometric studies and low procollagen type 1 amino-terminal propeptide and TRAcP circulating levels provide clear evidence of low bone turnover, explaining the observed defects in trabecular 
A

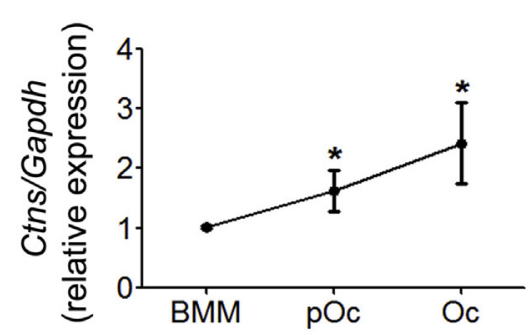

C

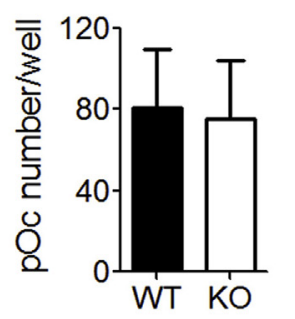

D

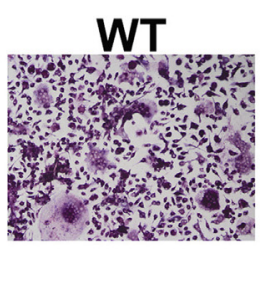

G
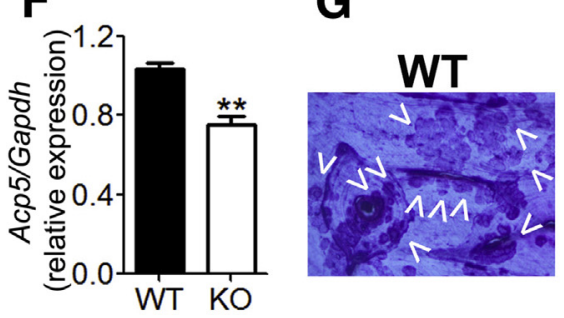

B

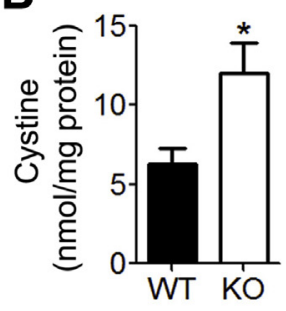

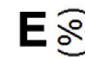

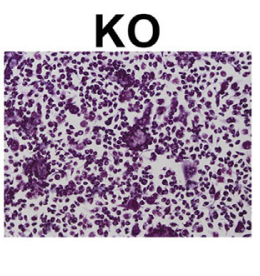

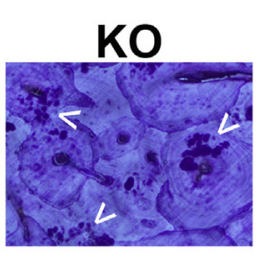

H

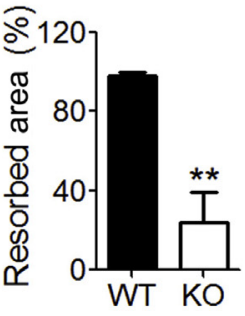

Figure 8 In vitro osteoclast analysis. A: Realtime RT-PCR analysis for cystinosin in wild-type (WT) bone marrow macrophage cells (BMMs), osteoclast precursors ( $\mathrm{p} 0 \mathrm{cs}$ ), and mature osteoclasts (Ocs). B: High-performance liquid chromatography measurement of cystine levels in osteoclasts isolated from WT (black bars) and cystinotic (K0; white bars) mice. C: Bone marrows were isolated from WT and $\mathrm{KO}$ animals, fixed after 3 hours, and stained for tartrate-resistant acid phosphatase (TRACP) to quantify osteoclast mononuclear precursors. D: Representative images of TRAcP-positive osteoclast cultures obtained from BMMs cultured in the presence of macrophage colony-stimulating factor and receptor activator of $\mathrm{NF}-\kappa \mathrm{B}$ ligand to induce osteoclastogenesis. E: Quantification of TRAcP-positive multinucleated (greater than three nuclei) cells. F: Real-time RTPCR expression analysis on RNA extracted from WT and $\mathrm{KO}$ osteoclast cultures using primer pairs and conditions specific for acp5. Values are normalized versus the housekeeping gene Gapdh. G: Representative images of blue toluidine-stained bone sections showing resorption lacunae (arrowheads) obtained from WT and KO osteoclasts. H: Quantification of resorbed area in WT and KO cultures. Values are normalized for osteoclast number. Results are reported as percentage versus WT osteoclast activity. Data are expressed as means \pm SEM $(\mathbf{A}-\mathbf{C}, \mathbf{E}, \mathbf{F}$, and $\mathbf{H}) .{ }^{*} P<0.05,{ }^{*} * P<0.005$ versus WT cells. Original magnification, $\times 10$ (D and $\mathbf{G})$.

bone. However, it cannot be excluded that the alterations of bone phenotype observed in 1-month-old KO mice may be due to defective skeletal development. Embryonic and fetal development studies should be performed to identify alterations of skeletal morphogenesis.

The in vitro studies confirmed that cystinosin deficiency affects differentiation and activity of both osteoclasts and osteoblasts. Indeed, KO osteoblasts showed a cellautonomous defect to mineralize. Although there is high variability among patients' skeletal alterations, a diffuse defective mineralization and scarce osteoblastic activity have been described in a patient's biopsy. ${ }^{9}$ Further studies are needed to evaluate whether reduced ability to mineralize could be related to impaired vesicle release and collagen deposition that could reflect the reduced osteoid surface in 1-month-old mice. Indeed, a failure to secrete collagen has been reported in chondrocytes of a mouse model of lysosomal storage defect. ${ }^{35}$ The impaired trafficking and the atypical clustering of lysosomes around the perinuclear area observed in cystinotic cells could explain how cystinosin deficiency affects osteoclast activity too. ${ }^{36}$ For their resorbing activity, osteoclasts need a tightly regulated trafficking of lysosomes and vesicles that release metalloproteinase 9 and cathepsin $\mathrm{K}$ in the bone resorption lacunae. An inhibition of the secretory machinery affects osteoclast function. ${ }^{37}$ However, the reduced osteoclastogenesis observed in $\mathrm{KO}$ cultures was in contradiction with data obtained from Claramunt-Taberner et $\mathrm{al}^{29}$ who demonstrated that patient mononuclear progenitors are more prone to generate osteoclasts than controls. However, the authors showed that even if cystinotic osteoclasts were increased in number, they were less active and cysteamine treatment further reduced their bone-resorbing ability. In agreement with these data, a strong reduction of the bone resorption activity was observed in KO osteoclasts. Taken together, these data provide evidence supporting the concept that bone growth is impaired in nephropathic cystinosis, independently from the Fanconi syndrome, chronic renal failure, and malnutrition. These defects were limited to the initial growth period, which corresponds approximately to preschool and early-school years in humans. At 3 months of age, no differences were observed between WT and KO animals. At this age, the rate of bone growth has already decreased substantially in mice, ${ }^{33}$ which probably explains lack of differences that are amplified only during periods of maximal growth. However, the spontaneous recovery of bone skeletal alterations was already documented in other genetic animal models. For example, the ia/ia incisor absent rat, showing an osteopetrotic phenotype due to loss of function of Plekhml (pleckstrin homology domain 
containing, family $\mathrm{M}$ member 1 ), developed a partial recovery of bone phenotype 30 to 50 days after birth. ${ }^{38}$ The understanding of molecular and cellular alterations that occur in the skeleton during growth and adulthood could explain the changes of bone phenotype observed in these transgenic animal models.

\section{Acknowledgments}

We thank the Center for Skeletal Research Core, Massachusetts General Hospital, for the micro-computed tomography analysis; and Dr. Corinne Antignac (INSERM U1163, Paris Descartes University, Paris, France) for providing C57BL/6 cystinotic and wild-type mice.

A.T. and A.D.F. designed the study; G.B., M.R., L.R.R., G.D.G., and M.D. performed experiments; A.P., O.P., F.E., A.T., and A.D.F. analyzed data. N.N., F.E., A.T., and A.D.F. interpreted data; A.T., A.D.F., and F.E. wrote the manuscript; F.E., O.P., and A.P. revised the manuscript; and A.T. is the guarantor of this work and, as such, had full access to all of the data in the study and takes responsibility for the integrity of the data and the accuracy of the data analysis.

\section{Supplemental Data}

Supplemental material for this article can be found at https://doi.org/10.1016/j.ajpath.2019.01.015.

\section{References}

1. Town M, Jean G, Cherqui S, Attard M, Forestier L, Whitmore SA, Callen DF, Gribouval O, Broyer M, Bates GP, van't Hoff W, Antignac C: A novel gene encoding an integral membrane protein is mutated in nephropathic cystinosis. Nat Genet 1998, 18:319-324

2. Kalatzis V, Cherqui S, Antignac C, Gasnier B: Cystinosin, the protein defective in cystinosis, is a $\mathrm{H}(+)$-driven lysosomal cystine transporter. EMBO J 2001, 20:5940-5949

3. Ruivo R, Anne C, Sagne C, Gasnier B: Molecular and cellular basis of lysosomal transmembrane protein dysfunction. Biochim Biophys Acta 2009, 1793:636-649

4. Wilmer MJ, Emma F, Levtchenko EN: The pathogenesis of cystinosis: mechanisms beyond cystine accumulation. Am J Physiol Renal Physiol 2010, 299:F905-F916

5. Emma F, Nesterova G, Langman C, Labbe A, Cherqui S, Goodyer P, Janssen MC, Greco M, Topaloglu R, Elenberg E, Dohil R, Trauner D, Antignac C, Cochat P, Kaskel F, Servais A, Wuhl E, Niaudet P, Van't Hoff W, Gahl W, Levtchenko E: Nephropathic cystinosis: an international consensus document. Nephrol Dial Transplant 2014, 29 Suppl 4:iv87-iv94

6. Ivanova E, De Leo MG, De Matteis MA, Levtchenko E: Cystinosis: clinical presentation, pathogenesis and treatment. Pediatr Endocrinol Rev 2014, 12 Suppl 1:176-184

7. Elmonem MA, Veys KR, Soliman NA, van Dyck M, van den Heuvel LP, Levtchenko E: Cystinosis: a review. Orphanet J Rare Dis 2016, 11:47

8. Sakarcan A: The Fanconi syndrome of cystinosis: insights into the pathophysiology. Turk J Pediatr 2002, 44:279-282

9. Bacchetta J, Greco M, Bertholet-Thomas A, Nobili F, Zustin J, Cochat P, Emma F, Boivin G: Skeletal implications and management of cystinosis: three case reports and literature review. Bonekey Rep 2016, 5:828

10. Sirrs S, Munk P, Mallinson PI, Ouellette H, Horvath G, Cooper S, Da Roza G, Rosenbaum D, O'Riley M, Nussbaumer G, Hoang LN, Lee CH: Cystinosis with sclerotic bone lesions. JIMD Rep 2014, 13:27-31

11. Florenzano P, Ferreira C, Nesterova G, Roberts MS, Tella SH, de Castro LF, Brown SM, Whitaker A, Pereira RC, Bulas D, Gafni RI, Salusky IB, Gahl WA, Collins MT: Skeletal consequences of nephropathic cystinosis. J Bone Miner Res 2018, 33:1870-1880

12. Gahl WA, Thoene JG, Schneider JA: Cystinosis. N Engl J Med 2002, $347: 111-121$

13. Klusmann M, Van't Hoff W, Monsell F, Offiah AC: Progressive destructive bone changes in patients with cystinosis. Skeletal Radiol 2014, 43:387-391

14. Cherqui S, Sevin C, Hamard G, Kalatzis V, Sich M, Pequignot MO, Gogat K, Abitbol M, Broyer M, Gubler MC, Antignac C: Intralysosomal cystine accumulation in mice lacking cystinosin, the protein defective in cystinosis. Mol Cell Biol 2002, 22:7622-7632

15. Conforti A, Taranta A, Biagini S, Starc N, Pitisci A, Bellomo F, Cirillo V, Locatelli F, Bernardo ME, Emma F: Cysteamine treatment restores the in vitro ability to differentiate along the osteoblastic lineage of mesenchymal stromal cells isolated from bone marrow of a cystinotic patient. J Transl Med 2015, 13:143

16. Committee for the Update of the Guide for the Care and Use of Laboratory Animals; National Research Council: Guide for the Care and Use of Laboratory Animals: Eighth Edition. Washington, DC, National Academies Press, 2011

17. Nevo N, Chol M, Bailleux A, Kalatzis V, Morisset L, Devuyst O, Gubler MC, Antignac C: Renal phenotype of the cystinosis mouse model is dependent upon genetic background. Nephrol Dial Transplant 2010, 25:1

18. Dempster DW, Compston JE, Drezner MK, Glorieux FH, Kanis JA, Malluche H, Meunier PJ, Ott SM, Recker RR, Parfitt AM: Standardized nomenclature, symbols, and units for bone histomorphometry: a 2012 update of the report of the ASBMR Histomorphometry Nomenclature Committee. J Bone Miner Res 2013, 28:2-17

19. Bouxsein ML, Boyd SK, Christiansen BA, Guldberg RE, Jepsen KJ, Muller R: Guidelines for assessment of bone microstructure in rodents using micro-computed tomography. J Bone Miner Res 2010, 25: $1468-1486$

20. Pastore A, Massoud R, Motti C, Lo Russo A, Fucci G, Cortese C, Federici G: Fully automated assay for total homocysteine, cysteine, cysteinylglycine, glutathione, cysteamine, and 2-mercaptopropionylglycine in plasma and urine. Clin Chem 1998, 44:825-832

21. Besouw M, Levtchenko E: Growth retardation in children with cystinosis. Minerva Pediatr 2010, 62:307-314

22. Nesterova G, Gahl WA: Cystinosis. Edited by Adam MP, Ardinger HH, Pagon RA, Wallace SE, Bean LJH, Stephens K, Amemiya A. In GeneReviews [Internet]. Copyright University of Washington, Seattle, 1993. Available at: https://www.ncbi.nlm.nih. gov/books/NBK1400 (last revised December 7, 2017)

23. Besouw MT, Schneider J, Janssen MC, Greco M, Emma F, Cornelissen EA, Desmet K, Skovby F, Nobili F, Lilien MR, De Paepe A, Malfait F, Symoens S, van den Heuvel LP, Levtchenko EN: Copper deficiency in patients with cystinosis with cysteamine toxicity. J Pediatr 2013, 163:754-760

24. Langman CB: Bone complications of cystinosis. J Pediatr 2017, 183s: $\mathrm{S} 2-\mathrm{S} 4$

25. Langman CB, Greenbaum LA, Grimm P, Sarwal M, Niaudet P, Deschenes G, Cornelissen EA, Morin D, Cochat P, Elenberg E, Hanna C, Gaillard S, Bagger MJ, Rioux P: Quality of life is improved and kidney function preserved in patients with nephropathic cystinosis treated for 2 years with delayed-release cysteamine bitartrate. J Pediatr 2014, 165:528-533.e1

26. Al-Hemidan A, Shoughy SS, Kozak I, Tabbara KF: Efficacy of topical cysteamine in nephropathic cystinosis. Br J Ophthalmol 2017, 101: 1234-1237 
27. Allison SJ: Therapy: an extended-release form of cysteamine bitartrate for cystinosis. Nat Rev Nephrol 2012, 8:374

28. Brodin-Sartorius A, Tete MJ, Niaudet P, Antignac C, Guest G, Ottolenghi C, Charbit M, Moyse D, Legendre C, Lesavre P, Cochat P, Servais A: Cysteamine therapy delays the progression of nephropathic cystinosis in late adolescents and adults. Kidney Int 2012, 81:179-189

29. Claramunt-Taberner D, Flammier S, Gaillard S, Cochat $P$, Peyruchaud O, Machuca-Gayet I, Bacchetta J: Bone disease in nephropathic cystinosis is related to cystinosin-induced osteoclastic dysfunction. Nephrol Dial Transplant 2018, 33:1525-1532

30. Kleta R, Bernardini I, Ueda M, Varade WS, Phornphutkul C, Krasnewich D, Gahl WA: Long-term follow-up of well-treated nephropathic cystinosis patients. J Pediatr 2004, 145:555-560

31. Nickolas TL, Stein EM, Dworakowski E, Nishiyama KK, KomandahKosseh M, Zhang CA, McMahon DJ, Liu XS, Boutroy S, Cremers S, Shane E: Rapid cortical bone loss in patients with chronic kidney disease. J Bone Miner Res 2013, 28:1811-1820

32. Bertholet-Thomas A, Claramunt-Taberner D, Gaillard S, Deschênes G, Sornay-Rendu E, Szulc P, Cohen-Solal M, Pelletier S, Carlier MC, Cochat $\mathrm{P}$, Bacchetta $\mathrm{J}$ : Teenagers and young adults with nephropathic cystinosis display significant bone disease and cortical impairment. Pediatr Nephrol 2018, 33:1165-1172
33. Van Stralen KJ, Emma F, Jager KJ, Verrina E, Schaefer F, Laube GF, Lewis MA, Levtchenko EN: Improvement in the renal prognosis in nephropathic cystinosis. Clin J Am Soc Nephrol 2011, 6:2485-2491

34. Stratikopoulos E, Szabolcs M, Dragatsis I, Klinakis A, Efstratiadis A: The hormonal action of IGF1 in postnatal mouse growth. Proc Natl Acad Sci U S A 2008, 105:19378-19383

35. Bartolomeo R, Cinque L, De Leonibus C, Forrester A, Salzano AC, Monfregola J, De Gennaro E, Nusco E, Isabella Azario I, Lanzara C, Serafini M, Levine B, Ballabio A, Settembre C: mTORC1 hyperactivation arrests bone growth in lysosomal storage disorders by suppressing autophagy. J Clin Invest 2017, 127:3717-3729

36. Ivanova EA, De Leo MG, Van Den Heuvel L, Pastore A, Dijkman H, De Matteis MA, Levtchenko EN: Endo-lysosomal dysfunction in human proximal tubular epithelial cells deficient for lysosomal cystine transporter cystinosin. PLoS One 2015, 10:e120998

37. Del Fattore A, Teti A, Rucci N: Bone cells and the mechanisms of bone remodelling. Front Biosci (Elite Ed) 2012, 4:2302-2321

38. Van Wesenbeeck L, Odgren PR, Coxon FP, Frattini A, Moens P, Perdu B, MacKay CA, Van Hul E, Timmermans JP, Vanhoenacker F, Jacobs R, Peruzzi B, Teti A, Helfrich MH, Rogers MJ, Villa A, Van Hul W: Involvement of PLEKHM1 in osteoclastic vesicular transport and osteopetrosis in incisors absent rats and humans. J Clin Invest 2007, 117:919-930 